\title{
Copolymerization of Tris(methoxyethoxy)vinyl Silane with N-Vinyl Pyrrolidone: Synthesis, Characterization, and Reactivity Relationships
}

\author{
Ameen Hadi Mohammed, ${ }^{1,2}$ Mansor Bin Ahmad, ${ }^{1}$ and Kamyar Shameli ${ }^{3}$ \\ ${ }^{1}$ Department of Chemistry, Faculty of Science, Universiti Putra Malaysia, 43400 Serdang, Selangor, Malaysia \\ ${ }^{2}$ Department of Chemistry, College of Science for Women, University of Baghdad, Al Jadria, Baghdad 10071, Iraq \\ ${ }^{3}$ Malaysia-Japan International Institute of Technology (MJIIT), Universiti Teknologi Malaysia, \\ Jalan Sultan Yahya Petra (Jalan Semarak), 54100 Kuala Lumpur, Malaysia
}

Correspondence should be addressed to Mansor Bin Ahmad; mansorahmad@gmail.com

and Kamyar Shameli; kamyarshameli@gmail.com

Received 5 March 2015; Accepted 15 April 2015

Academic Editor: Angel Concheiro

Copyright (C) 2015 Ameen Hadi Mohammed et al. This is an open access article distributed under the Creative Commons Attribution License, which permits unrestricted use, distribution, and reproduction in any medium, provided the original work is properly cited.

\begin{abstract}
Copolymer of tris(methoxyethoxy)vinyl silane (TMEVS) with N-vinyl pyrrolidone (NVP) was synthesized by free radical polymerization in dry benzene at $70^{\circ} \mathrm{C}$ using benzoyl peroxide (BPO) as initiator. The copolymer was characterized by viscometer, FTIR, and ${ }^{1} \mathrm{H}-\mathrm{NMR}$ and its thermal properties were studied by DSC and TGA. The copolymer composition was determined by elemental analysis. The monomer reactivity ratios were calculated by linearization methods proposed by Fineman-Ross and KelenTudos. The intersection method was proposed by Mayo-Lewis and nonlinear method was proposed by curve-fitting procedure. The microstructure of copolymer and sequence distribution of monomers in the copolymer were calculated by statistical method.
\end{abstract}

\section{Introduction}

Copolymerization is the most successful and powerful method for effecting systematic changes in polymer properties [1]. Copolymerization modulates both the intramolecular and intermolecular forces exercised between like and unlike polymer segments and consequent properties such as glass transition temperature, melting point, solubility, permeability, dye ability, adhesion, elasticity, and chemical reactivity may be varied within wide limits. The utility of copolymerization is exemplified on one hand by the fundamental investigations of structure property relation and on the other hand by the wide range of commercial and biology applications $[2,3]$.

Reactivity ratios are among the most important parameters for a composition equation of copolymers, which can offer information such as relative reactivity of monomer pairs and estimate the copolymer composition. Knowledge of the copolymer composition is an important step in the evolution of its utility. Copolymer composition and its distribution are dependent on the reactivity ratios. The calculation of the monomer reactivity ratios requires the mathematical treatment of experimental data on the compositions of copolymers and monomers feed mixtures. Many methods have been used to estimate reactivity ratios of a large number of comonomers [4]. In order to determine the amount of the comonomer that has been incorporated into the copolymer, various analytical methods must be used: nitrogen analysis, Fourier Transform Infrared Spectroscopy, Proton and Carbon Nuclear Magnetic Resonance, and ultraviolet-visible spectroscopy [5-7].

The interests in polymers and copolymers which contain silicon atom have been increasing due to their hydrophobicity and wide applications as optical, semiconductor materials, and electric and ceramic processes. In radical copolymerization of vinyl silane monomers with various other monomers, the reactivity of vinyl silane monomers is strongly depending on the position of the silicon atom relative to the vinyl 


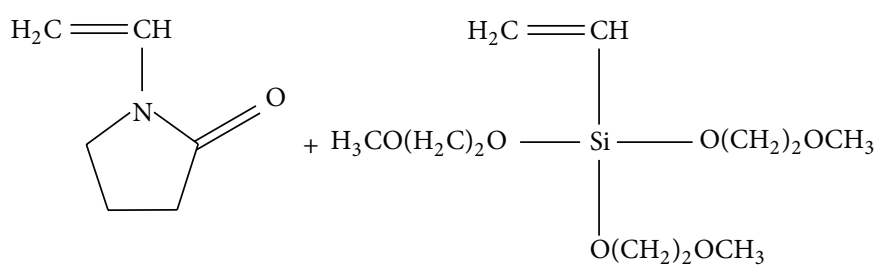

$\mathrm{N}$-Vinyl pyrrolidone (NVP)
Tris(methoxyethoxy)vinyl silane

(TMEVS)

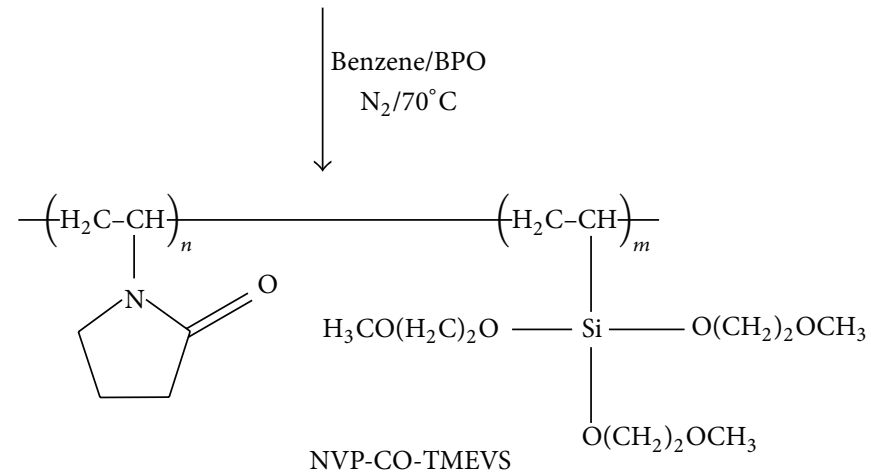

SCHEME 1: Schematic illustration of the process formation of NVP-CO-TMEVS copolymer from NVP and TMEVS as monomers.

group $[8,9]$; the reactivity ratio of these monomers is zero if the $\mathrm{Si}$ atom is beside the vinyl group because of $\mathrm{d} \pi-$ $\mathrm{p} \pi$ interactions between the vinyl group and the $\mathrm{Si}$ atom. On the other hand, it should be possible to increase the reactivity of vinyl silane monomers by copolymerization with comonomers that have poor reactivity with themselves. In fact, vinyl silane monomers have been successfully copolymerized with styrene, butyl acrylate methacrylic acid, methyl methacrylate, acrylonitrile, 2-vinyl pyridine, vinyl sulfonate esters, and other monomers [10-14].

$\mathrm{N}-$ Vinyl pyrrolidone (NVP) and its copolymers are attracting much attention and have been widely investigated for applications in different field due to its low toxicity, biocompatibility, and good film form [15-22]. The amide group in NVP is highly polar, which confirms that it is hydrophilic. NVP has been copolymerized with various monomers [23-25] because the amide group has high affinity for many large and small molecules that are known to be good hydrogen-bond acceptors. NVP has been copolymerized with various siloxane derivatives monomers such as vinyl triethoxy silane, vinyl trimethoxy silane, vinyl trimethyl silane, vinyl trichlorosilane, and 3-(trimethoxysilyl)propyl methacrylate. In addition, the reactivity ratios of these copolymers have been determined [26-29], but no one has copolymerized and studied the reactivity relationships of NVP with tris(methoxyethoxy)vinyl silane (TMEVS).

The aim of this work is the copolymerization of TMEVS, a hydrophobic monomer with NVP, a hydrophilic monomer, to find the best synthetic conditions and characterization of the copolymer. To determine the reactivity ratios of TMEVS and NVP, from these parameters, a specific comonomer distribution should be estimated.

\section{Experimental Section}

2.1. Materials. Commercial samples of NVP and TMEVS from Aldrich chemical were distilled under vacuum before copolymerization. Benzoyl peroxide was recrystallized twice from chloroform and dried in a vacuum. Solvents of $99 \%$ purity grade were used as received.

2.2. Synthesis of Copolymers. Copolymerization of NVP with TMEVS was carried out by using $\left(1 \times 10^{-3} \mathrm{~mol} / \mathrm{dm}^{3}\right) \mathrm{BPO}$ as initiator and dry benzene as solvent at $70^{\circ} \mathrm{C}$ in a glass tube. The total molar composition of the monomer mixture was maintained at $1 \mathrm{~mol} / \mathrm{dm}^{3}$ while the monomer feed ratio was varied in a series of copolymerizations of NVP and TMEVS (NVP-CO-TMEVS). Nitrogen gas was bubbled through the mixture for 10 minutes prior to the reaction in order to remove all oxygen. Copolymerization time was controlled to obtain low conversion $(<10 \%)$. The copolymers were isolated by precipitation in diethyl ether. The precipitates were filtered off and purified by dissolving again in benzene and precipitated in diethyl ether. Copolymers were dried in vacuum at $40^{\circ} \mathrm{C}$ until constant weight. The reaction of copolymerization is shown in Scheme 1.

2.3. Copolymer Characterization. Perken Elmer-1650 spectrometer was used to record FTIR spectra of the copolymers on $\mathrm{KBr}$ Pellets in the range $200-4000 \mathrm{~cm}^{-1}$. The $\mathrm{H}-\mathrm{NMR}$ was recorded with a JOEL JMTC-500/54/SS $(500 \mathrm{MHz})$ spectrometer using DMSO as solvent and tetramethyl silane as internal standard. The solubility of the copolymers was studied using various organic solvent and water at room 


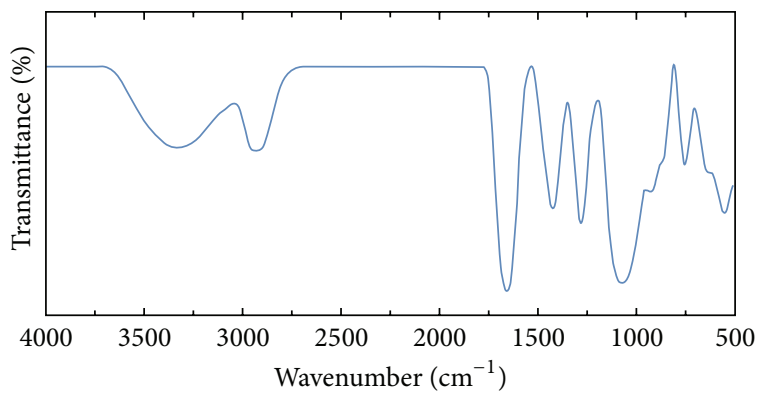

FIGURE 1: FTIR of TMEVS/NVP copolymer.

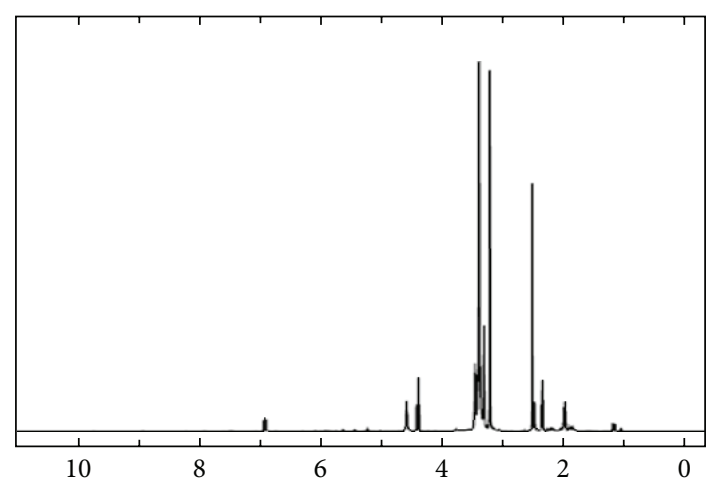

FIGURE 2: ${ }^{1} \mathrm{H}-\mathrm{NMR}$ of TMEVS/NVP copolymer.

temperature for 24 hours. Intrinsic viscosity [ $\mathrm{y}$ ] was determined according to the Solomon Gottesman relationship [30] by using an Ostwald Viscometer with negligible kinetic energy correction. Copolymer compositions were estimated by elemental analysis following the variation of estimated nitrogen content arising from vinyl pyrrolidone comonomers units. Thermal degradability of the polymer was studied by TGA using Perkin Elmer in a nitrogen atmosphere at a heating rate of $10^{\circ} \mathrm{C} / \mathrm{min}$ from 0 to $800^{\circ} \mathrm{C}$ and glass transition temperature $\left(T_{g}\right)$ was determined using a DSCMettler calorimetric system.

\section{Results and Discussion}

The structure of the copolymer is confirmed by FITR as shown in Figure 1. The comparative study between the FTIR spectra of the copolymer and monomers shows disappearance absorption bands of the monomers: stretching $\mathrm{C}-\mathrm{H}$ of double bond $3010-3100 \mathrm{~cm}^{-1}$, stretching $\mathrm{C}=\mathrm{C}$ of the vinyl group at about $1610-1680 \mathrm{~cm}^{-1}$, and bending $\mathrm{C}-\mathrm{H}$ of the vinyl group at about $900-1000 \mathrm{~cm}^{-1}$. In addition, many absorption bands appear in the FTIR spectra of the copolymer which belong to the stretching vibration in different functional groups of corresponding monomers: 2935 (Alkan C-H), 1655 (tertiary amide carbonyl), 1422 (amide C-N), 1278 (ether $\mathrm{C}-\mathrm{O}), 1080(\mathrm{Si}-\mathrm{O})$, and $751 \mathrm{~cm}^{-1}(\mathrm{Si}-\mathrm{C})$.

Figure 2 shows H-NMR spectrum of the copolymer. When the copolymer and monomers spectra are compared

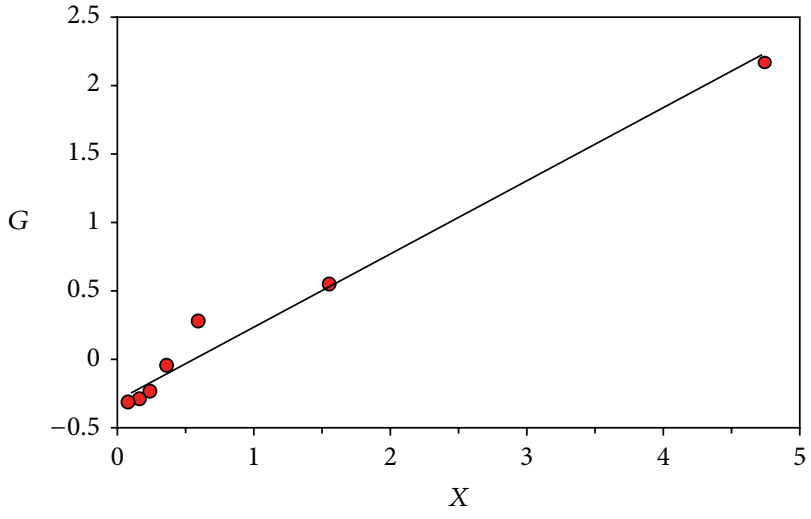

FIgURE 3: Fineman-Ross plot of TMEVS/NVP copolymer.

in H-NMR study, the signal belongs to the vinyl protons of the monomers that disappeared from the region close to $6.0 \mathrm{ppm}$. Moreover, for the copolymer, methylene protons in NVP ring resonate in $2.5,3.2$, and 4.4 , while $\mathrm{CH}_{2}$ protons main chain backbone of monomers resonates at 1.8-2.4. The signal corresponding to the protons of the ethoxy groups linked to the silicon atom in TMEVS at about 3.6 can be clearly observed and the protons of ethoxy groups linked to methyl groups at 3.4. Signals for $\mathrm{CH}_{3}$ groups of TMEVS appear at 3.3. $\mathrm{CH}$ protons of the two monomers resonate at 4.6.

3.1. Copolymer Composition. It is very important to study the comonomer reactivity in the copolymers systems because the composition of these copolymers depends on the monomer feed composition. In TMEVS/NVP polymer, composition of the monomer in the copolymer was determined by estimating $\mathrm{N} \%$ in the copolymer and this percentage indirectly gave the mole fraction of NVP in the copolymer. The copolymers are insoluble in most of the solvents but they are soluble in some specific solvents, like benzene, DMF, and DMSO. The monomer composition and the results of elemental analysis in addition to intrinsic viscosity values [n] for samples of seven different compositions are listed in Table 1 . The values of $[\eta]$ should be used in estimating qualitatively degree of polymerization.

3.2. Reactivity Ratio. The most common mathematical model of copolymerization is based on finding the relationship between the composition of copolymers and the composition of the monomer feed in which the monomer reactivity ratios are the parameters to be determined [31].

In our investigation several methods have been proposed for the best fitting of $\left(r_{1} \& r_{2}\right)$ pair from a set of $\left[M_{1}\right],\left[M_{2}\right]$, $d\left[M_{1}\right]$, and $d\left[M_{2}\right]$ pair, using linearization methods proposed by Fineman and Ross [32], Kelen and Tüdös [33], and Mayo and Lewis [34] and with the nonlinear method proposed by curve-fitting [35] procedures, data are given in Tables 2 and 3 and showed in Figures 3, 4, 5, and 6, respectively. 
TABLE 1: Feed and copolymer compositions, conversion, and intrinsic viscosity [ $\mathrm{\eta}$ ] of TMEVS/NVP copolymer.

\begin{tabular}{lccccc}
\hline Test number & $f_{1}($ feed $)$ & Conversion $\%$ & $\mathrm{~N} \%$ & $F_{1}($ copolymer $)$ & 0.714 \\
\hline 1 & 0.782 & 9.5 & 1.834 & 0.608 & 2.47 \\
2 & 0.609 & 9.1 & 2.551 & 0.595 & 1.78 \\
3 & 0.481 & 9.4 & 2.675 & 0.490 & 0.35 \\
4 & 0.369 & 9.9 & 3.693 & 0.375 & 0.97 \\
5 & 0.275 & 8.3 & 5.004 & 0.316 & 0.92 \\
6 & 0.205 & 8.8 & 5.784 & 0.250 & 0.88 \\
7 & 0.137 & 8.7 & 6.802 & 0 & 0.81 \\
\hline
\end{tabular}

$f_{1}$ is the mole fraction of monomer-1 (TMEVS) in the initial feed; $f_{2}=1-f_{1}$.

$F_{1}$ is the mole fraction of monomer-1 (TMEVS) in the copolymer; $F_{2}=1-F_{1}$.

TABLE 2: Fineman-Ross, Kelen-Tudos, and Mayo-Lewis parameters of TMEVS/NVP.

\begin{tabular}{|c|c|c|c|c|c|c|c|}
\hline \multirow{2}{*}{ Test number } & \multirow{2}{*}{$f_{1}$} & $G=f(F-1) / F$ & $X=f^{2} / F$ & $N=G /(\alpha+X)$ & $A=X /(\alpha+X)$ & $1 / F$ & $F$ \\
\hline & & \multicolumn{2}{|c|}{ Fineman \& Ross } & \multicolumn{2}{|c|}{ Kelen \& Todus } & \multicolumn{2}{|c|}{ Mayo \& Lewis } \\
\hline 1 & 0.782 & 2.181 & 4.748 & 0.394 & 0.891 & 0.399 & 3.584 \\
\hline 2 & 0.609 & 0.559 & 1.551 & 0.259 & 0.729 & 0.643 & 1.557 \\
\hline 3 & 0.481 & 0.291 & 0.589 & 0.255 & 0.500 & 0.678 & 0.926 \\
\hline 4 & 0.369 & -0.038 & 0.354 & -0.024 & 0.379 & 1.043 & 0.584 \\
\hline 5 & 0.275 & -0.231 & 0.231 & -0.305 & 0.290 & 1.666 & 0.379 \\
\hline 6 & 0.205 & -0.282 & 0.142 & -0.401 & 0.196 & 2.159 & 0.258 \\
\hline 7 & 0.137 & -0.316 & 0.072 & -0.484 & 0.110 & 3.000 & 0.158 \\
\hline
\end{tabular}

$\alpha=\left(X_{\min } \times X_{\max }\right)^{1 / 2}=0.584$.

TABLE 3: Theoretical parameters with values $r_{1}=0.505$ and $r_{2}=$ 0.331 of TMEVS/NVP.

\begin{tabular}{lccc}
\hline$M_{1} / M_{2}$ & $d\left[M_{1}\right] / d\left[M_{2}\right]$ & $f_{2}$ & $F_{2}$ \\
\hline 0.1 & 0.233 & 0.909 & 0.811 \\
0.5 & 0.735 & 0.606 & 0.576 \\
1 & 1.111 & 0.500 & 0.473 \\
2 & 1.702 & 0.333 & 0.370 \\
4 & 2.758 & 0.200 & 0.266 \\
6 & 3.770 & 0.209 & 0.142 \\
9 & 5.524 & 0.100 & 0.158 \\
\hline
\end{tabular}

One has the following:

$$
\begin{aligned}
& F=\frac{d\left[M_{1}\right]}{d\left[M_{2}\right]}, \\
& f=\frac{\left[M_{1}\right]}{\left[M_{2}\right]} .
\end{aligned}
$$

For mathematical details of these procedures, the original papers [32-35] should be consulted. The values from the different methods are very close, even those obtained by the inverse Fineman-Ross graph.

Table 4 shows the values of reactivity ratios by different methods. With the values of $r_{1}$ and $r_{2}$, the variation of the instantaneous mole fraction $F_{2}$ of NVP in copolymer (at low conversion) with the mole fraction $f_{2}$ in the initial feed may

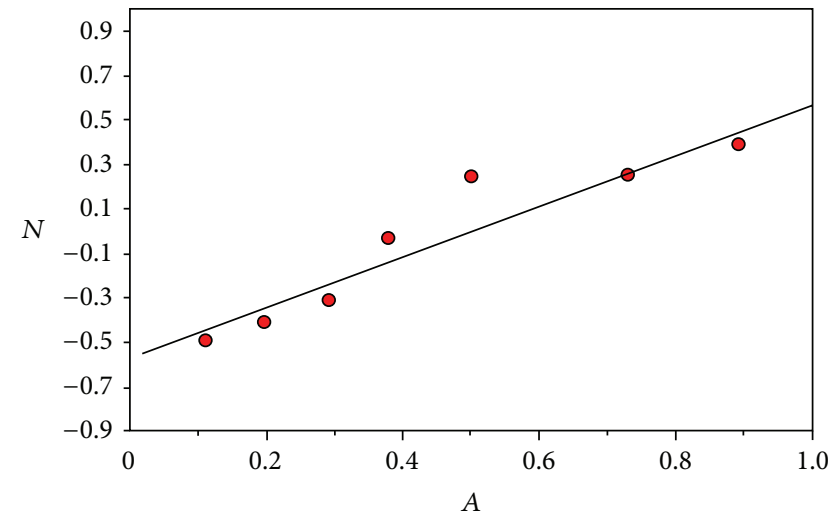

FIgURE 4: Kelen-Tudos plot of TMEVS/NVP copolymer.

be calculated using the copolymer composition equation in the form

$$
\frac{F_{1}}{F_{2}}=\frac{f_{1}\left(r_{1} f_{1}+f_{2}\right)}{f_{2}\left(r_{2} f_{2}+f_{1}\right)} .
$$

Figure 6 shows the theoretical curve (solid line) follows closely the experimental copolymer composition data, in which we have the following:

(a) For $f_{1}=0-0.41$ (the azeotropic composition) $F_{1}>$ $f_{1}$.

(b) For $f_{1}=0.41-1.0, F_{1}<f_{1}$.

An azeotropic composition is possible when $r_{1}$ and $r_{2}$ are both greater than 1 and less than 1 . This condition is fulfilled 


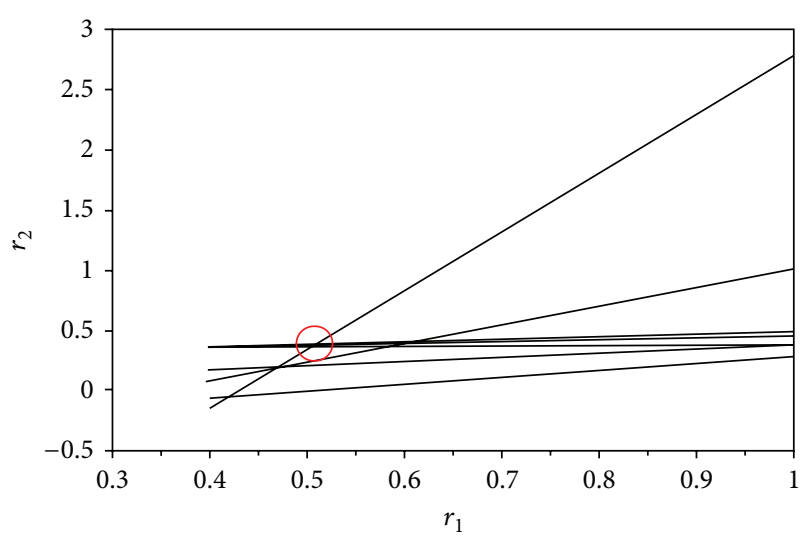

FIGURE 5: Mayo-Lewis plot of TMEVS/NVP copolymer.

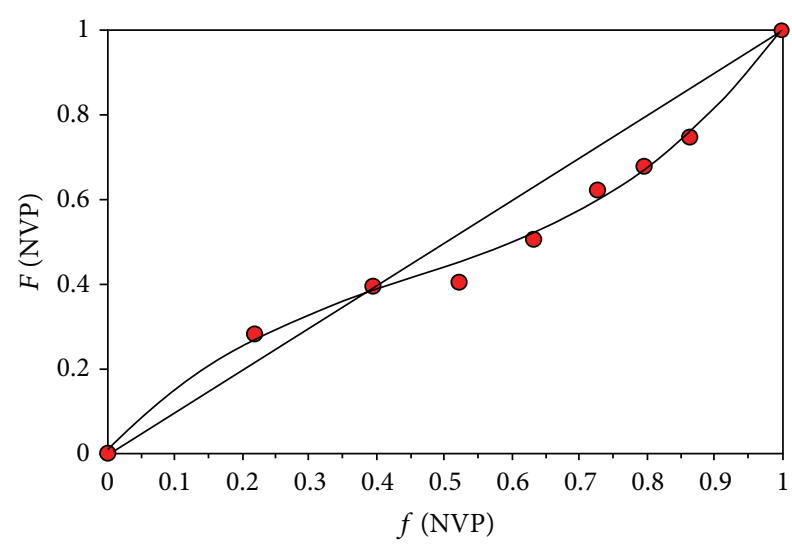

FIGURE 6: Copolymer composition of TMEVS/NVP. The black solid line represents the theoretical curve calculated from the copolymer composition equation for $r_{1}=0.505$ and $r_{2}=0.331$, which follows closely the experimental copolymer composition data that is mentioned by red circle colour.

TABLE 4: Monomer reactivity ratios of TMEVS/NVP copolymer.

\begin{tabular}{lcc}
\hline Procedure & TMEVS & NVP \\
& $r_{1}$ & $r_{2}$ \\
\hline Fineman-Ross & 0.502 & 0.327 \\
Kelen-Tudos & 0.498 & 0.318 \\
Mayo-Lewis & 0.513 & 0.336 \\
Curve-fitting & 0.505 & 0.331 \\
Average values & 0.504 & 0.328 \\
& \pm 0.009 & \pm 0.008 \\
\hline
\end{tabular}

in TMEVS/NVP system since $r_{1}$ and $r_{2}$ are both less than unity. The corresponding azeotropic feed composition $f_{2}$ (az.) is given by

$$
f_{2}(\mathrm{az})=\frac{\left(1-r_{1}\right)}{\left(2-r_{1}-r_{2}\right)} .
$$

A value of 0.41 obtained for $f_{2}$ (az.) in TMEVS/NVP system.
TABLE 5: Structural data of TMEVS/NVP copolymer.

\begin{tabular}{|c|c|c|c|c|c|}
\hline \multirow{2}{*}{ Test number } & \multicolumn{2}{|c|}{ Copolymer } & \multicolumn{2}{|c|}{ Blockness (mol\%) } & \multirow{2}{*}{$\begin{array}{c}\text { Alternation } \\
\text { (mol\%) } \\
M_{1}-M_{2}\end{array}$} \\
\hline & $F_{1}$ & $F_{2}$ & $M_{1}$ & $M_{2}$ & \\
\hline 1 & 0.714 & 0.286 & 45.61 & 2.08 & 52.31 \\
\hline 2 & 0.608 & 0.392 & 28.24 & 6.65 & 65.11 \\
\hline 3 & 0.595 & 0.405 & 26.49 & 7.33 & 66.18 \\
\hline 4 & 0.490 & 0.509 & 13.57 & 15.26 & 71.16 \\
\hline 5 & 0.375 & 0.625 & 5.08 & 30.13 & 64.79 \\
\hline 6 & 0.316 & 0.684 & 3.55 & 40.18 & 56.27 \\
\hline 7 & 0.250 & 0.750 & 1.16 & 51.45 & 47.39 \\
\hline
\end{tabular}

In this study, TMEVS was copolymerized with NVP in spite of the fact that the copolymerization of vinyl silane derived monomers is difficult [36-38].

The reactivity of TMEVS 0.5 is of the same order as reactivity of NVP 0.32 due to the electron attraction and electronic delocalization effects of NVP and oxygen atoms of TMEVS and for this reason attendance to random copolymer forming can be postulated; that is, both $r_{1}$ and $r_{2}$ are between 0 and 1 .

There are six electrons-attracting oxygen atoms for each monomer unit of TMEVS, giving rise to a significant attraction of the free electron generated in the growing polymer chain with corresponding stabilization of the [...TMEVS $\left.{ }^{*}\right]$ macroradical; for this reason the value of reactivity of TMEVS (0.5) is more than the reactivity of vinyl trimethyl silane VTMS (0.074), vinyl trimethoxy silane VTMOS (0.407), and vinyl triethoxy silane VTEOS (0.3), when they were copolymerized with NVP $[8,26]$.

3.3. Copolymer Microstructure. The statistical distribution of the monomers in the formation of the copolymer 1-1, 2-2, and 1-2 is listed in Table 5 and is calculated using the following relations [39]:

$$
\begin{aligned}
& S_{1-1}=m_{1}-\frac{2 m_{1} m_{2}}{1}+\left[\left(2 m_{1}-1\right)^{2}+4 r_{1} r_{2} m_{1} m_{2}\right]^{1 / 2}, \\
& S_{2-2}=m_{2}-\frac{2 m_{1} m_{2}}{1}+\left[\left(2 m_{1}-1\right)^{2}+4 r_{1} r_{2} m_{1} m_{2}\right]^{1 / 2}, \\
& S_{1-2}=\frac{4 m_{1} m_{2}}{1}+\left[\left(2 m_{1}-1\right)^{2}+4 r_{1} r_{2} m_{1} m_{2}\right]^{1 / 2},
\end{aligned}
$$

where $m_{1}$ and $m_{2}$ are the mole fractions of TMEVS and NVP in the copolymer, $r_{1}$ and $r_{2}$ are the reactivity ratios, and $S_{1-1}, S_{2-2}$, and $S_{1-2}$ are the mole fractions of 1-1, 2-2, and 1-2 sequences, respectively. 
TABLE 6: Statistical data of TMEVS/NVP copolymer.

\begin{tabular}{|c|c|c|c|c|c|c|}
\hline \multirow{2}{*}{ Test number } & \multicolumn{4}{|c|}{ Sequence probability } & \multicolumn{2}{|c|}{ Sequence length } \\
\hline & PAA & PBB & $\mathrm{PAB}$ & PBA & $\mu_{1}$ & $\mu_{2}$ \\
\hline 1 & 0.642 & 0.088 & 0.357 & 0.911 & 2.801 & 1.097 \\
\hline 2 & 0.438 & 0.183 & 0.562 & 0.817 & 1.778 & 1.225 \\
\hline 3 & 0.316 & 0.274 & 0.683 & 0.726 & 1.463 & 1.377 \\
\hline 4 & 0.226 & 0.374 & 0.774 & 0.626 & 1.292 & 1.598 \\
\hline 5 & 0.159 & 0.480 & 0.841 & 0.520 & 1.189 & 1.922 \\
\hline 6 & 0.114 & 0.576 & 0.886 & 0.425 & 1.129 & 2.355 \\
\hline 7 & 0.073 & 0.688 & 0.926 & 0.312 & 1.079 & 3.204 \\
\hline
\end{tabular}

The probabilities of finding the sequence of TMEVS and NVP units are listed in Table 6 and calculated as follows:

$$
\begin{aligned}
& P A A=\frac{r_{1}[A]}{r_{1}[A]}+[B], \\
& P B B=\frac{r_{2}[B]}{r_{2}[B]}+[A], \\
& P A B=\frac{[B]}{r_{1}[A]}+[B], \\
& P B A=\frac{[A]}{r_{2}[B]}+[A],
\end{aligned}
$$

where $P A A, P B B, P A B$, and $P B A$ are the probability of a TMEVS or NVP unit to be followed by TMEVS or NVP unit. In these equations $[A]$ and $[B]$ are the mole fractions of TMEVS and NVP in the feed. The average length sequences of TMEVS and NVP are listed in Table 6 and calculated using the following equations:

$$
\begin{aligned}
& \mu_{1}=\frac{1}{P A B}, \\
& \mu_{2}=\frac{1}{P B A} .
\end{aligned}
$$

The mole fractions of 1-1 and 2-2 sequences increase as the mole fractions of TMEVS and NVP increase. On the other hand, the 1-2 sequence is between 47 and 71, which indicates both the monomers have a tendency to react with other monomers in the growing chain and form random copolymer and this is in agreement with the values of $r_{1}(0.5)$ and $r_{2}(0.32)$; both are between 0 and 1 .

The mean sequence length of TMEVS $\mu_{1}$ varied from 2.081 to 1.079 for these copolymer compositions; values of $\mu_{2}$ NVP were between 1.097 and 3.204.

3.4. Thermal Properties. The thermal properties of copolymer TMEVS/NVP were studied by TGA and DSC. TGA was carried out in the temperature range of $0-800^{\circ} \mathrm{C}$ under nitrogen atmosphere and is presented in Figure 7 with initial thermal decomposition at $220^{\circ} \mathrm{C}, 10 \%$ at about $395,50 \%$ at about 465 , and $30 \%$ residual at $800^{\circ} \mathrm{C}$. Figure 8 shows the DSC thermogram of copolymer indicating $T_{g}$ being $290^{\circ} \mathrm{C}$.

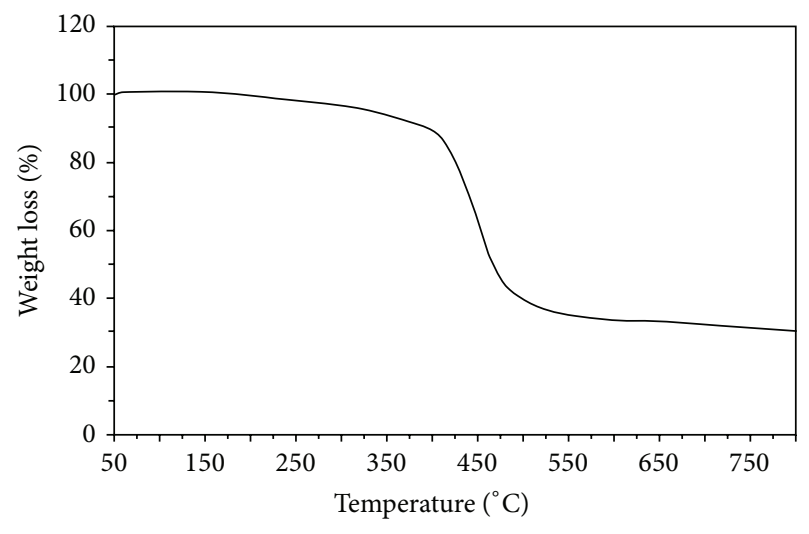

FIGURE 7: TGA of TMEVS/NVP copolymer.

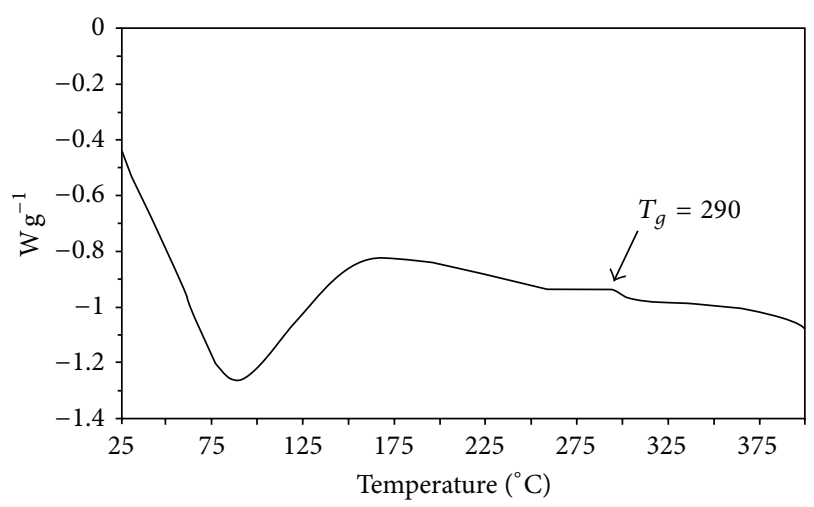

FIGURE 8: DSC of TMEVS/NVP copolymer.

\section{Conclusion}

TMEVS/NVP copolymer was synthesized by free radical polymerization. The structure of copolymer was confirmed by FTIR and ${ }^{1} \mathrm{H}-\mathrm{NMR}$ techniques. Copolymer compositions were obtained by elemental analysis. The reactivity ratios were obtained by Fineman-Ross, Kelen-Tudo, MayoLewis, and curve-fitting methods and a good agreement was observed between the various methods. The value of $r_{\text {TMEVs }}=$ 0.504 is of the same order as $r_{\mathrm{NVP}}=0.328$ due to the electronic delocalization and electronegative oxygen atoms of NVP and TMEVS so this copolymer can be classified 
as a random copolymer. The microstructure and sequence distribution are in agreement with the values of reactivity ratios.

\section{Conflict of Interests}

The authors declare that there is no conflict of interests regarding the publication of this paper.

\section{References}

[1] A. K. Patel, R. J. Patel, K. H. Patel, and R. M. Patel, "Synthesis, characterization, thermal properties and antimicrobial activity of acrylic copolymers derived from 2,4-dichlorophenyl acrylate," Journal of the Chilean Chemical Society, vol. 54, no. 3, pp. 228-233, 2009.

[2] F. H. Schacher, P. A. Rupar, and I. Manners, "Functional block copolymers: nanostructured materials with emerging applications," Angewandte Chemie-International Edition, vol. 51, no. 32, pp. 7898-7921, 2012.

[3] H. A. S. Schoonbrood, A. M. Aerdts, A. L. German, and G. P. M. van der Velden, "Determination of the intra- and intermolecular microstructure of bulk and emulsion copolymers of styrene and 2-hydroxyethyl methacrylate by means of proton NMR and gradient polymer elution chromatography," Macromolecules, vol. 28 , no. 16 , pp. 5518-5525, 1995.

[4] A. L. Polic, T. A. Duever, and A. Penlidis, "Case studies and literature review on the estimation of copolymerization reactivity ratios," Journal of Polymer Science Part A: Polymer Chemistry, vol. 36, no. 5, pp. 813-822, 1998.

[5] S. Ashenagar, F. Ziaee, and S. M. Jalilian, "Calculation of reactivity ratios of methacrylic acid-ethyl acrylate copolymer by on-line quantitative ${ }^{1} \mathrm{H}$ NMR spectroscopy," Iranian Polymer Journal, vol. 22, no. 9, pp. 635-639, 2013.

[6] A. M. Parambil, Y. M. Puttaiahgowda, and P. Shankarappa, "Copolymerization of N-Vinyl pyrrolidone with methyl methacrylate by $\mathrm{Ti}(\mathrm{III})-\mathrm{DMG}$ redox initiator," Turkish Journal of Chemistry, vol. 36, no. 3, pp. 397-409, 2012.

[7] M. G. Patel, H. J. Patel, K. H. Patel, and R. M. Patel, "Synthesis and characterization of novel acrylic copolymers: determination of monomer reactivity ratios and antimicrobial activity," Malaysian Polymer Journal, vol. 3, no. 1, pp. 14-26, 2008.

[8] N. Gatica, F. R. Díaz, L. Gargallo, and D. Radić, "Vineyltrimethylsilane-co-N-vinyl-2-pyrrolidone and vinylmethoxysilane-co-N-vinyl-2-pyrrolidone copolymers," Polymer Bulletin, vol. 40, pp. 707-713, 1998.

[9] T. M. Stefanac, M. A. Brook, and R. Stan, "Radical reactivity of hydrovinylsilanes: homooligomers," Macromolecules, vol. 29, no. 13, pp. 4549-4555, 1996.

[10] C. Tasdelen-Yucedag and A. T. Erciyes, "Modification of polycaprolactone-styrene-vinyl trimethoxysilane terpolymer with sunflower oil for coating purposes," Progress in Organic Coatings, vol. 77, no. 11, pp. 1750-1760, 2014.

[11] Y. Wu, R. Yu, L. Hu, Q. Li, and C. Zhu, "Thermal stability of cocured blends of vinyl trimethoxysilane and aryl acetylene resins with different posttreatments," Journal of Applied Polymer Science, vol. 131, no. 8, pp. 1-6, 2014.

[12] H. Mori, Y. Saito, E. Takahashi, K. Nakabayashi, A. Onuma, and M. Morishima, "Synthesis of sulfonated organic-inorganic hybrids through the radical copolymerization of vinyl sulfonate esters and vinyl trialkoxysilanes," Reactive and Functional Polymers, vol. 73, no. 4, pp. 658-667, 2013.
[13] X.-L. Wang and B. Yan, "Photofunctional binary and ternary $\mathrm{Eu}^{3+} / \mathrm{Tb}^{3+}$ hybrid materials with copolymer linkage methacrylic acid-vinyltrimethoxysilane and 1,10-phenanthroline," Colloids and Surfaces A: Physicochemical and Engineering Aspects, vol. 399, pp. 18-24, 2012.

[14] W. W. Cui, D. Y. Tang, and L. L. Guan, "Synthesis and electrochemical properties of poly(lithium 2-acrylamido-2methylpropanesulfonate-co-vinyl triethoxysilane)-based interpenetrating network type single-ion conducting polymer gel electrolytes," Advanced Science Letters, vol. 5, no. 2, pp. 485-491, 2012.

[15] A. L. Harreus, R. Backes, J. O. Eichler et al., Ullmann's Encyclopedia of Industrial Chemistry, Wiley-VCH, 2011.

[16] P. Hemalatha, M. K. Veeraiah, S. Prasannakumar, and K. V. Anasuya, "Synthesis, characterisation and antibacterial activity of copolymer (N-vinylpyrrolidone-maleic anhydride) with $\mathrm{N}$ diethylethanolamine," International of Research in Engineering and Technology, vol. 3, no. 3, pp. 56-64, 2014.

[17] P. Hemalatha, M. K. Veeraiah, S. P. Kumar et al., "Antibacterial properties of poly(N-vinylpyrrolidone-co-acrylic acid)/ diethylaminoethanol ester," Indian Journal of Advances in Chemical Science, vol. 2, pp. 50-54, 2014.

[18] K. V. Anasuya, M. K. Veeraiah, S. Prasannakumar, P. Hemalatha, and M. Manju, "Synthesis and characterisation of polyvinyl pyrrolidon)-cobalt(II) complexes," Indian Journal of Advances in Chemical Science, vol. 2, pp. 12-15, 2014.

[19] S. Vijayasekaran, T. V. Chirila, Y. Hong et al., "Poly(1-vinyl2-pyrrolidinone) hydrogels as vitreous substitutes: histopathological evaluation in the animal eye," Journal of Biomaterials Science, Polymer Edition, vol. 7, no. 8, pp. 685-696, 1996.

[20] H. Y. Lee, S. A. Yu, K. H. Jeong, and Y. J. Kim, "Poly(vinyl pyrrolidone) conjugated lipid system for the hydrophobic drug delivery," Macromolecular Research, vol. 15, no. 6, pp. 547-552, 2007.

[21] F. Huma, Z. Akhter, T. Yasin, M. Zafar-Uz-Zaman, and A. Manan, "Crosslinking of poly(N-vinyl pyrrolidone-co-n-butyl methacrylate) copolymers for controlled drug delivery," Polymer Bulletin, vol. 71, no. 2, pp. 433-451, 2014.

[22] J. Li, S. Nie, L. Wang, S. Sun, F. Ran, and C. Zhao, "One-pot synthesized poly(vinyl pyrrolidone-co-methyl methacrylateco- acrylic acid) blended with poly(ether sulfone) to prepare blood-compatible membranes," Journal of Applied Polymer Science, vol. 130, no. 6, pp. 4284-4298, 2013.

[23] S. Jin, J. Gu, Y. Shi, K. Shao, X. Yu, and G. Yue, "Preparation and electrical sensitive behavior of poly (N-vinylpyrrolidoneco-acrylic acid) hydrogel with flexible chain nature," European Polymer Journal, vol. 49, no. 7, pp. 1871-1880, 2013.

[24] S. Santanakrishnan, M. Stach, I. Lacík, and R. A. Hutchinson, "Aqueous-phase copolymerization of $\mathrm{N}$-vinylpyrrolidone and N-vinylformamide," Macromolecular Chemistry and Physics, vol. 213, no. 13, pp. 1330-1338, 2012.

[25] P. Arosio, M. Mosconi, G. Storti, and M. Morbidelli, "Precipitation copolymerization of vinyl-imidazole and vinylpyrrolidone, 1-experimental analysis," Macromolecular Reaction Engineering, vol. 5, no. 9-10, pp. 490-500, 2011.

[26] N. L. Gatica, N. F. Fernández, A. Opazo, S. Alegría, L. Gargallo, and D. Radic, "Synthesis and characterization of functionalized vinyl copolymers. Electronegativity and comonomer reactivity in radical copolymerization," Polymer International, vol. 52, no. 8, pp. 1280-1286, 2003. 
[27] M. N. Gorbunova and E. A. Sazonova, "Sorption ability of Nvinylpyrrolidone-trimethoxyvinylsilane copolymers," Russian Journal of Applied Chemistry, vol. 81, no. 10, pp. 1863-1864, 2008.

[28] N. Gatica, N. Fernández, A. Opazo, and D. Radic, "Synthesis and characterization of functionalized vinyl copolymers I. Structure-monomer reactivity relationship in copolymers containing N-vinyl-2-pyrrolidone moieties," Journal of the Chilean Chemical Society, vol. 50, no. 3, pp. 99-108, 2005.

[29] M. Tao, F. Liu, and L. Xue, "Persistently hydrophilic microporous membranes based on in situ cross-linking," Journal of Membrane Science, vol. 474, pp. 224-232, 2015.

[30] M. Nachman and K. Kwiatkowski, "The effect of thermal annealing on the abrasion resistance of a segmented block copolymer urethane elastomers," Wear, vol. 306, no. 1-2, pp.113118, 2013.

[31] N. Ayaz, F. Bezgin, and K. Demirell1, "Polymers based on methacrylate bearing coumarin side group: synthesis via free radical polymerization, monomer reactivity ratios, dielectric behavior, and thermal stabilities," ISRN Polymer Science, vol. 2012, Article ID 352759, 13 pages, 2012.

[32] M. Fineman and S. D. Ross, "Linear method for determining monomer reactivity ratios in copolymerization," Journal of Polymer Science, vol. 5, no. 2, pp. 259-262, 1950.

[33] T. Kelen and F. Tüdös, "Analysis of the linear methods for determining copolymerization reactivity ratios: a new improved linear graphic method," Journal of Macromolecular Science: Part A-Chemistry, vol. 9, no. 1, pp. 1-27, 1975.

[34] F. R. Mayo and F. M. Lewis, "Copolymerization. I. A basis for comparing the behavior of monomers in copolymerization; the copolymerization of styrene and methyl methacrylate," Journal of the American Chemical Society, vol. 66, no. 9, pp. 1594-1601, 1944.

[35] T. Alfrey, J. J. Bohrer, and H. Mark, Copolymerzzution, InterScience, New York, NY, USA, 1952.

[36] V. L. Rao and G. N. Babu, "Copolymerization of styrene, acrylonitrile and methyl methacrylate with $\gamma$-methacryloxypropyl trimethoxy silane," European Polymer Journal, vol. 25, no. 6, pp. 605-609, 1989.

[37] W. Yao, Y. Li, and X. Huang, "Fluorinated poly(meth)acrylate: synthesis and properties," Polymer, vol. 55, no. 24, pp. 6197-6211, 2014.

[38] V. L. Rao and G. N. Babu, "Copolymerization of acrylonitrile with functional silanes," Journal of Macrolecular Science, vol. 20, no. 5-6, pp. 527-537, 1983.

[39] S. Igarashi, "Representation of composition and blockiness of the copolymer by a triangular coordinate system," Journal of Polymer Science Part B: Polymer Letters, vol. 1, no. 7, pp. 359363, 1963. 

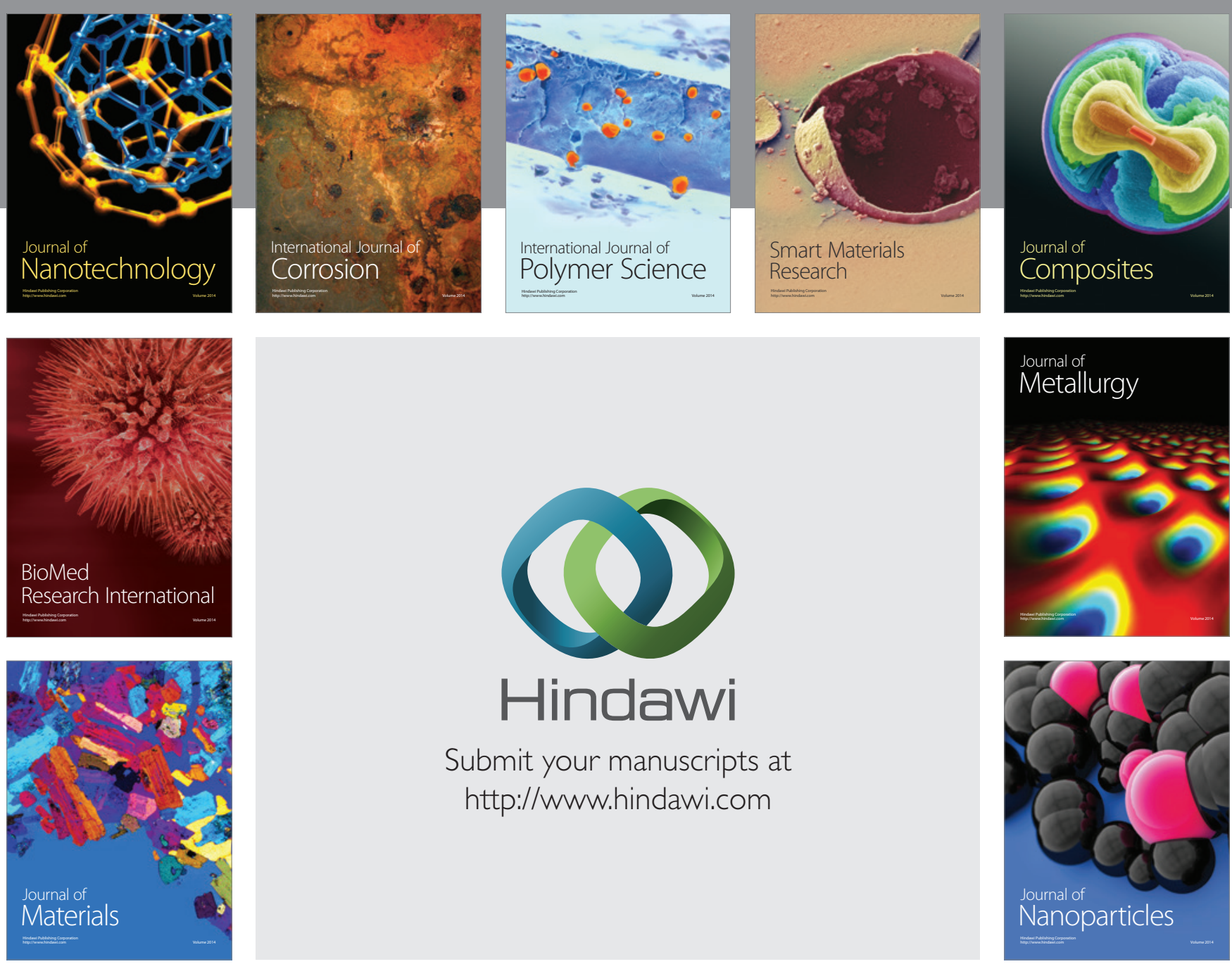

Submit your manuscripts at http://www.hindawi.com
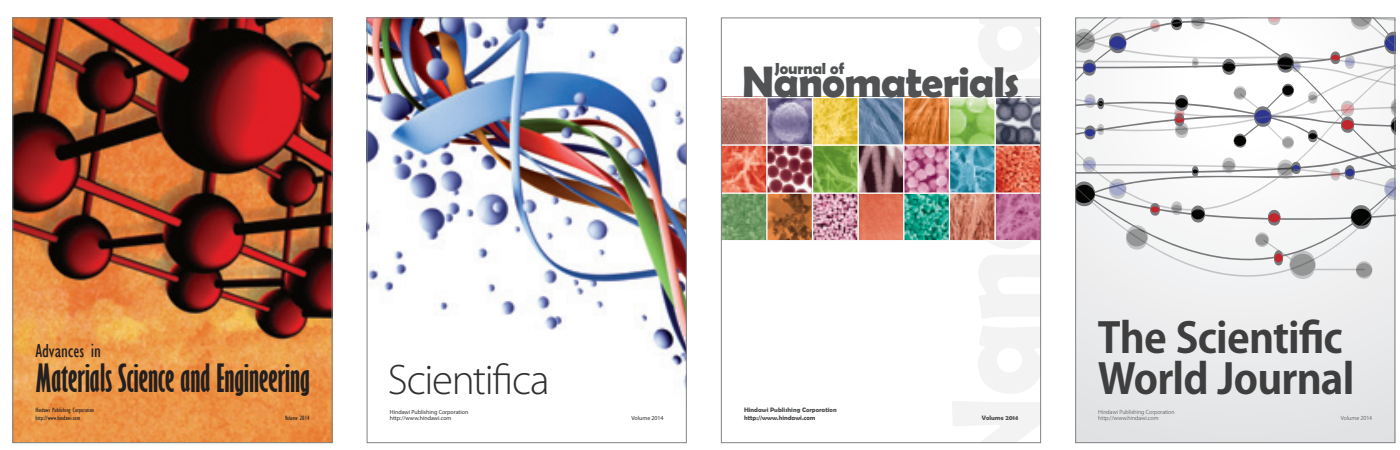

\section{The Scientific World Journal}
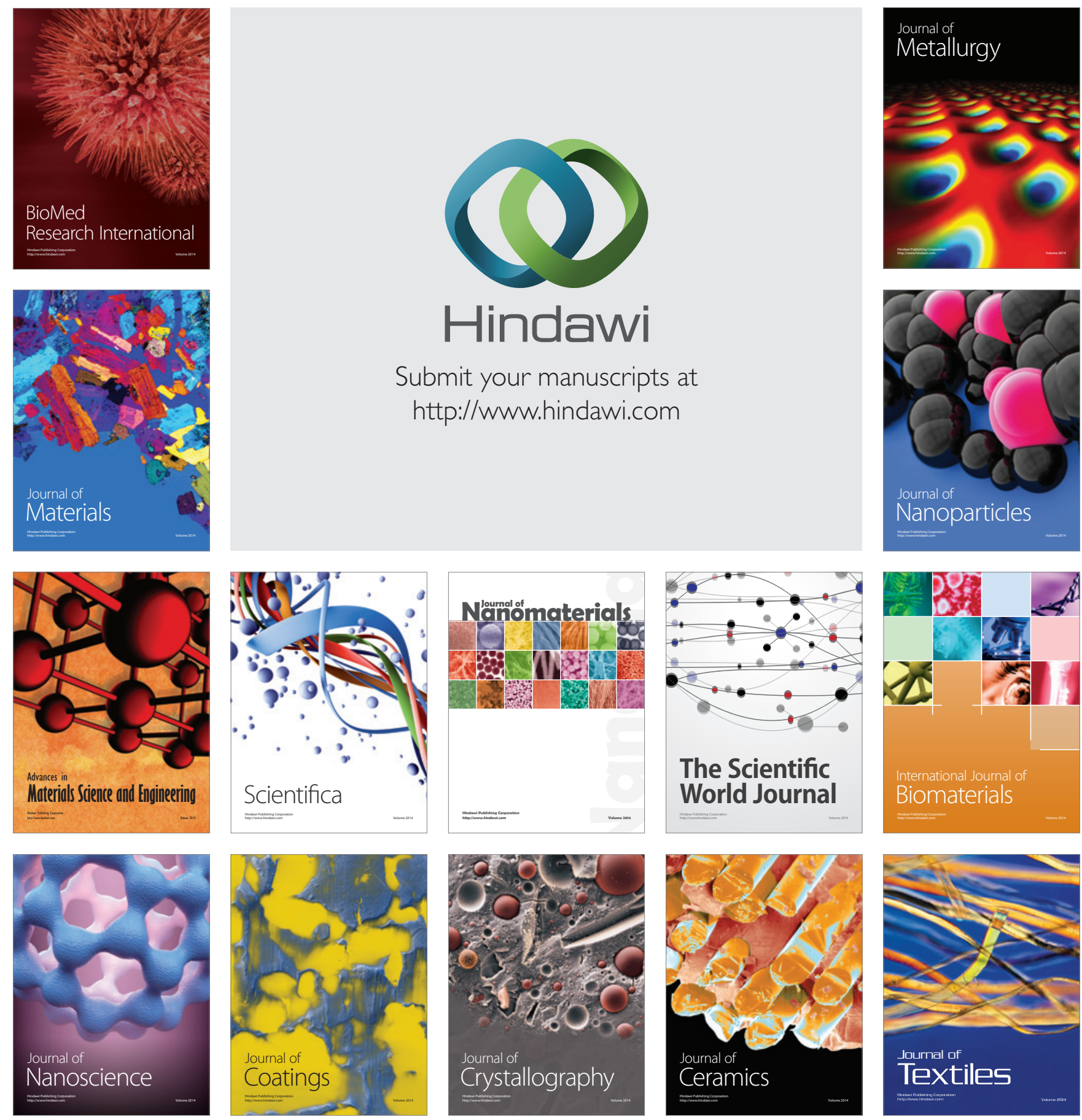